\title{
DSM-5 and the Decision Not to Include Sex, Shopping or Stealing as Addictions
}

\author{
Marcelo Piquet-Pessôa • Gabriela M. Ferreira • \\ Isabela A. Melca • Leonardo F. Fontenelle
}

Published online: 12 June 2014

(C) Springer International Publishing AG 2014

\begin{abstract}
For the first time substance use will not be required for the diagnosis of addiction in diagnostic classification manuals, such as DSM and ICD. The DSM-5 has included gambling disorder, along with substance use disorders, as forms of addictions in a new chapter named "Substancerelated and addictive disorders", thus reflecting evidence that gambling behaviors activate reward systems similarly to drugs of abuse. However, there is still debate on whether other less recognized forms of impulsive behaviors, such as compulsive buying (oniomania), compulsive sex, and kleptomania can be conceptualized as addictions. In this review, we critically evaluate the literature on these behaviors with a focus on socio-demographic and clinical characteristics, underlying neurobiology and treatment response, and their potential overlap with substance use disorders. We were unable to find a substantial number of studies supporting a relationship of the aforementioned reward-based conditions to substance use disorders, thus supporting the contention not to include compulsive buying, compulsive sex, and kleptomania in DSM-5 as behavioral addictions.
\end{abstract}

Keywords Compulsive buying · Compulsive shopping · Compulsive sex · Hypersexual disorder · Kleptomania · Shoplifting $\cdot$ Behavioral addictions $\cdot$ DSM-5

\footnotetext{
M. Piquet-Pessôa $(\varangle) \cdot$ G. M. Ferreira $・$ I. A. Melca $•$

L. F. Fontenelle

Anxiety and Obsessive-Compulsive Disorders Research Program, Institute of Psychiatry of the Federal University of Rio de Janeiro, Avenida Venceslau Brás 71 fundos Botafogo, Rio de Janeiro, RJ 22290-140, Brazil

e-mail: marcelo.piquet@gmail.com

L. F. Fontenelle

D'Or Institute for Research and Education, Rio de Janeiro, Brazil
}

\section{Introduction}

For many years, former $D S M$ versions employed the term addiction in relation to alcohol and substance use, while the pursuit of non-substance reward (e.g., excessive gambling, food and sex) was described as symptomatic of impulse control disorders or personality disorders. In DSM-5, for the first time since the diagnostic manuals were developed, the diagnosis of addiction will no longer be limited to substance use [1]. For instance, pathological gambling, now termed gambling disorder, has been described as a behavioral addiction under the chapter named "Substance-related and addictive disorders", reflecting evidence that gambling behaviors activate reward systems, similarly to drugs of abuse $[2,3]$. In fact, there has been growing evidence that other behaviors with positive reinforcing effects may become addictive for predisposed individuals. However, the mechanisms underlying other behavioral addictions are poorly understood, in part because of the lack of animal models and brain imaging research $[4 \bullet \cdot]$.

Although a number of reward-based conditions (such as excessive eating, sex and love, buying, exercising, gaming, tanning, tatooing, shoplifting etc.), present some phenomenological overlap with behavioral addictions, the evidence suggesting that these behaviors may develop into addictions is mostly descriptive, rather than biological or evidence-based [5]. However, the evidence suggesting that some of them (such as gambling), share features with substance use disorder is compelling. Both diagnostic groups tend to have an early age of onset and high prevalence in adolescents and young adults. The co-occurrence of behavioral addiction with substance use disorders suggests that they share dysfunction in overlapping neurocircuitry pathways involving the frontal cortex and the striatum [4*0]. Also, the patterns of comorbidities in both conditions are similar, involving depressive disorders, bipolar disorders, and ADHD. 
In terms of natural history, initial behavioral addictions' and substance use disorders' ego-syntonic features gradually become more habitual, automatic, compulsive and egodystonic. Attempts to discontinue problematic behaviors in both conditions are associated with increased levels of dysphoria. There have also been some reports of patients who switch from substance use disorders to behavioral addictions and vice-versa [6]. In addition, both may be viewed as pathological variants of normative behavior; it is sometimes difficult to set the threshold for clinical significance, which may be considered arbitrary. Finally, they often respond to the same pharmacological and psychosocial treatments, such as the 12step based approach, cognitive behavior therapy, mu-opioids receptor antagonists, and medications that alter glutamatergic activity $[7 \bullet \bullet]$.

While the evidence supporting the inclusion of gambling disorder as a behavioral addiction in DSM-5 was considered sufficient, there is still debate on whether other, less recognized forms of abnormal behaviors, such as compulsive buying, compulsive sex or hypersexual disorder, and kleptomania, can be conceptualized as addictions. In this review, we critically evaluate the literature on these behaviors with a focus on socio-demographic features, clinical characteristics, treatment response and their potential overlap with substance used disorders.

\section{Compulsive Buying}

Emil Kraepelin first described compulsive buying as an impulsive insanity almost a hundred years ago [8]. Studies have shown that this condition is more prevalent in women and has its onset in the late teens and early adulthood. People suffering from compulsive buying experience repetitive, irresistible, and overpowering urges to purchase goods. In general, the goods are inexpensive and useless [9]. The diagnosis requires evidence of severe distress or interference in social, financial and occupational areas. An important difference between compulsive buyers, normal consumers, and hoarders with excessive acquisition is that the focus and excitement is not on the item bought, but on the buying process itself [10].

In compulsive buying, the overpowering urge to buy, the repetitive loss of control over spending, and the negative emotional state that emerges when not buying resemble craving, drug seeking behavior, and withdrawal symptoms in substance use disorders. Accordingly, some patients report a feeling similar to the "high" resulting from drug intoxication while performing the buying act. As in substance use disorders, positive reinforcement plays a role at the beginning of compulsive buying, while negative reinforcement is involved in the long-term maintenance of the behavior [10]. Psychiatric comorbidities in both include mood disorders, eating disorders, and other impulse control disorders. Some studies suggest that nearly $60 \%$ of compulsive buying patients meet criteria for at least one personality disorder [11].

We found only one fMRI study showing a higher activity in the ventral striatum and a lower activation of the insula while compulsive buying patients performed purchasing related decisions [12•]. Although a role has been suggested for opiate, serotonergic, and dopaminergic systems dysfunctions in this condition, the precise alterations in these neurotransmitters are still unclear [6]. For instance, the evidence supporting the utility of serotonin reuptake inhibitors in compulsive buying is mixed, i.e., while citalopram has shown some benefit [13], escitalopram [14] and fluvoxamine did not $[15,16]$. One additional concern is that the number of different buying behaviors required to qualify compulsive buying as potentially addictive, is unclear [17]. Thus, we concur with the DSM-5 developers in that there is not enough data to classify compulsive buying as an addiction.

\section{Hypersexual Disorder}

In the 19th century, individuals who lost control over sexual behaviors were diagnosed with moral insanity, satyriasis, or nymphomania [18]. The prevalence of hypersexual disorder is estimated to be between 3 and $6 \%$ [19]. The condition is far more common among men, begins in adolescence and early adulthood, and has a chronic course [19]. It can be hard to draw limits between hypersexual disorder and normal sexual behavior, which depends on partner's behavior, societal and moral values, and ethics and religious beliefs [20]. However, hypersexual disorder has been reported to be associated with unwanted outcomes, such as unplanned pregnancy, marital separation and divorce, and sexually transmitted diseases, including HIV infection [21, 22].

Although not formally recognized in $D S M-5$ as a discrete psychiatric disorder, hypersexual disorder shares some features with substance use disorders. These include an early onset with a chronic-relapsing course that comprises pursuit of short-term reward (i.e., orgasm in hypersexual disorder or a "high" in substance use disorders), despite potential long-term negative consequences (e.g., physical or emotional harm to self or others), and frustrated attempts to inhibit or control the behavior [21]. Some have argued that, like addiction, hypersexual disorder patients may develop tolerance to increasing levels of sexual stimulation, and even withdrawal-like syndromes in the absence of sexual activities, although there are no high quality data available to prove or disprove this observation. Thus, if hypersexual disorder exists as a discrete psychiatric disorder that is independent from other existing nosological entities, phenomenological data 
suggests that it could be classified as a behavioral addiction [21].

However, there is also some evident phenomenological overlap between hypersexual disorder and other groups of psychiatric disorders. For instance, it could be also classified as a non-paraphilic sexual desire disorder, as an obsessivecompulsive related disorder, or as a disruptive, impulse control, or conduct-related disorder [21]. The identification of neurobiological links between hypersexual disorder and the conditions listed under these headings could help to establish its place in the current nosological scenario. However, there seems to be no obvious answer to this question, as there is a dearth of biological studies on the topic. For instance, we are aware of only one imaging study in hypersexual disorder. In a diffusion tensor imaging (DTI), Miner et al., found affected subjects to have significantly higher superior frontal region mean diffusivity than controls, which correlated with the severity of symptoms $[23 \cdot \bullet]$.

The lack of neurobiological studies in other areas is also noteworthy. While the same DTI study reported above found hypersexual disorder patients to show higher impulsivity scores when compared to controls in a go-non-go task [23••], another study reported cognitive rigidity, poor judgment, and deficits in emotional regulation in affected subjects [24]. There is also some evidence suggesting that hypersexual disorder may involve dysfunction in dopaminergic pathways, as hypersexuality and other uncontrolled behaviors (e.g., compulsive buying), are reported to be occasional side effects of dopamine agonists in Parkinson's disease patients [25]. Involvement of the frontal lobes, increased impulsivity, poor emotional regulation, and a relationship with disturbed dopaminergic neurotransmission suggest hypersexual disorder to be associated with behavioral addiction. However, given the scarcity of biological studies in the field, we feel that the DSM5 decision not to include it as a behavioral addiction was justifiable and prudent one.

\section{Kleptomania}

In 1938, Esquirol, a French psychiatrist, coined the term kleptomania as a way to describe an irresistible impulse to steal worthless objects. Although the terms shoplifting and kleptomania have been used interchangeably, the goal for the latter is generally symptom relief without financial purposes [26]. While the prevalence of kleptomania in the general population is somewhere between 0.3 and $0.6 \%$ [2], shoplifting is far more common, affecting up to $11.3 \%$ of the population in their lifetime [27]. Although most stolen objects are worthless and inexpensive, shoplifters are responsible for almost US $\$ 11.7$ billion in retail losses per year in the USA [28]. Kleptomania affects more women than men and begins in adolescence and early adulthood [29].
Typically, once a kleptomania patient steals an item, the stolen items are hoarded, thrown away, or secretly returned. Most patients keep the condition secret until consequences become severe. In fact, patients usually present for treatment by legal mandate due to repeated shoplifting [30]. Kleptomania is associated with high rates of suicide attempts [31]. Some cases are triggered by medications (e.g., serotonin reuptake inhibitors) [32], and may emerge during specific medical conditions, such as Neuro-Behçet's disease [33]. Studies have found high lifetime rates of comorbid mood (59 to $100 \%$ ), anxiety (60 to $80 \%$ ), impulse control (20 to $46 \%$ ), and substance use disorders (23 to $50 \%$ ) [34].

Currently, kleptomania is under the chapter "Disruptive, Impulse-Control, and Conduct Disorders" in the DSM-5 [2]. However, as the compulsive component becomes more evident, researchers have suggested that it should be best characterized either as an obsessive-compulsive related disorder, or as a behavioral addiction. While the first view is based on the presence of repetitive thoughts, irresistible urges and uncontrolled behaviors related to stealing, and on the high rate (63\%) of hoarding found among patients with kleptomania [7••]; the disorder also resembles substance use disorders on phenomenological and, at least preliminarily, on the biological level.

Like many other impulse control disorders, kleptomania is characterized by a chronic relapse pattern, with pursuit of short term reward, the sense of a "high" while committing the act, successive attempts to control or stop the behavior, and feeling of shame and guilt after the behavior. From the neurobiological standpoint, studies showing poor white matter integrity in ventral-medial-frontal regions [35•], positive response to opioid antagonists [36••], and lack of response to serotonin reuptake inhibitors [37], all suggest that kleptomania may be classified as a behavioral addiction. However, to date, neurobiological studies are too few to provide a definitive answer with regard to the nosological status of this condition.

\section{Conclusion}

Although there is a consensus on the identification of gambling disorder as a behavioral addiction, there is no agreement on whether other excessive behaviors with mixed impulsive and compulsive features (such as compulsive buying, hypersexual disorder, and kleptomania), are related to substance use disorder and should therefore be considered as behavioral addiction. In addition to neuroimaging, which has begun to unveil similarities and differences among individual behavioral addictions, and between behavioral addictions and SUD, further molecular, cognitive, and computational research will be valuable in delineating the boundaries and location of behavioral addictions in dimensions of psychopathology [4••]. 


\section{Compliance with Ethics Guidelines}

Conflict of Interest Marcelo Piquet-Pessôa, Gabriela M. Ferreira, Isabela A. Melca, and Leonardo F. Fontenelle, declare no conflict of interest.

Human and Animal Rights and Informed Consent This article does not contain any studies with human or animal subjects performed by any of the authors.

\section{References}

Papers of particular interest, published recently, have been highlighted as:

- Of importance

-. Of major importance

1. Frascella J, Potenza MN, Brown LL, Childress AR. Shared brain vulnerabilities open the way for nonsubstance addictions: carving addiction at a new joint? Ann N Y Acad Sci. 2010;1187:294-315. doi:10.1111/j.1749-6632.2009.05420.x.

2. APA. Diagnostic and statistical manual of mental disorders: DSM-5. Arlington: American Psychiatric Publishing Incorporated; 2013.

3. Holden C. Psychiatry. Behavioral addictions debut in proposed DSM-V. Science. 2010;327(5968):935. doi:10.1126/science.327. 5968.935.

4.• Leeman RF, Potenza MN. A targeted review of the neurobiology and genetics of behavioural addictions: an emerging area of research. Can J Psychiatry. 2013;58(5):260-73. Very interesting review providing an overview of the psychobiological basis of behavioral addictions.

5. Grant JE, Potenza MN, Weinstein A, Gorelick DA. Introduction to behavioral addictions. Am J Drug Alcohol Abuse. 2010;36(5):23341. doi:10.3109/00952990.2010.491884.

6. Guillou-Landreat M, Grall-Bronnec M, Venisse JL. Behavioral addictions. Presse Med. 2012;41(12 Pt 1):1271-5. doi:10.1016/j. lpm.2012.07.024.

7.• Grant JE, Schreiber LR, Odlaug BL. Phenomenology and treatment of behavioural addictions. Can J Psychiatry. 2013;58(5):252-9. Very important review providing summarizing psychological research on behavioral addictions. Together with the review by Leeman and Potenza on the same number of Canadian Journal of Psychiatry, this review constitute an important source of information on the validity of different types of behavioral addictions.

8. Kraepelin E. Psychiatrie. Leipzig: Verlag Von Johann Ambrosius Barth; 1915.

9. Lejoyeux M, Weinstein A. Compulsive buying. Am J Drug Alcohol Abuse. 2010;36(5):248-53. doi:10.3109/00952990. 2010.493590.

10. Muller A, Mitchell JE, de Zwaan M. Compulsive buying. Am J Addict. 2013. doi:10.1111/j.1521-0391.2013.12111.x.

11. Schlosser S, Black DW, Repertinger S, Freet D. Compulsive buying. Demography, phenomenology, and comorbidity in 46 subjects. Gen Hosp Psychiatry. 1994;16(3):205-12.

12. Raab G, Elger C, Neuner M, Weber B. A neurological study of compulsive buying behaviour. J Consum Policy. 2011;34(4):401-13. doi:10.1007/s10603-011-9168-3. Although small, this study showed higher activity in the ventral striatum and a lower activation of the insula while $C B$ patients performed purchasing related decisions.

13. Koran LM, Chuong HW, Bullock KD, Smith SC. Citalopram for compulsive shopping disorder: an open-label study followed by double-blind discontinuation. J Clin Psychiatry. 2003;64(7):793-8.

14. Koran LM, Aboujaoude EN, Solvason B, Gamel NN, Smith EH. Escitalopram for compulsive buying disorder: a double-blind discontinuation study. J Clin Psychopharmacol. 2007;27(2):225-7. doi:10.1097/01.jcp.0000264975.79367.f4.

15. Black DW, Gabel J, Hansen J, Schlosser S. A double-blind comparison of fluvoxamine versus placebo in the treatment of compulsive buying disorder. Ann Clin Psychiatry. 2000;12(4):205-11.

16. Ninan PT, McElroy SL, Kane CP, Knight BT, Casuto LS, Rose SE, et al. Placebo-controlled study of fluvoxamine in the treatment of patients with compulsive buying. J Clin Psychopharmacol. 2000;20(3):362-6.

17. Hartston $\mathrm{H}$. The case for compulsive shopping as an addiction. $\mathrm{J}$ Psychoactive Drugs. 2012;44(1):64-7.

18. Levine SB. What is sexual addiction? J Sex Marital Ther. 2010;36(3):261-75. doi:10.1080/00926231003719681.

19. Kaplan MS, Krueger RB. Diagnosis, assessment, and treatment of hypersexuality. J Sex Res. 2010;47(2):181-98. doi:10.1080/ 00224491003592863.

20. Karim R, Chaudhri P. Behavioral addictions: an overview. J Psychoactive Drugs. 2012;44(1):5-17.

21. Kafka MP. Hypersexual disorder: a proposed diagnosis for DSM-V. Arch Sex Behav. 2010;39(2):377-400. doi:10.1007/s10508-0099574-7.

22. Kafka MP. "What is sexual addiction?" A response to Stephen Levine. J Sex Marital Ther. 2010;36(3):276-81. doi:10.1080/ 00926231003719707.

23.• Miner MH, Raymond N, Mueller BA, Lloyd M, Lim KO. Preliminary investigation of the impulsive and neuroanatomical characteristics of compulsive sexual behavior. Psychiatry Res. 2009;174(2):146-51. doi:10.1016/j.pscychresns.2009.04.008. An important study showing that hypersexual disorder is associated with white matter integrity problems along with increased impulsivity.

24. Reid RC, Garos S, Carpenter BN, Coleman E. A surprising finding related to executive control in a patient sample of hypersexual men. J Sex Med. 2011;8(8):2227-36. doi:10.1111/j.1743-6109.2011. 02314.x.

25. Vilas D, Pont-Sunyer C, Tolosa E. Impulse control disorders in Parkinson's disease. Parkinsonism Relat Disord. 2012;18 Suppl 1: S80-4. doi:10.1016/S1353-8020(11)70026-8.

26. Grant JE, Odlaug BL, Kim SW. Kleptomania: clinical characteristics and relationship to substance use disorders. Am J Drug Alcohol Abuse. 2010;36(5):291-5. doi:10.3109/ 00952991003721100.

27. Blanco C, Grant J, Petry NM, Simpson HB, Alegria A, Liu $\mathrm{SM}$, et al. Prevalence and correlates of shoplifting in the United States: results from the National Epidemiologic Survey on Alcohol and Related Conditions (NESARC). Am J Psychiatry. 2008;165(7):905-13. doi:10.1176/appi.ajp.2008. 07101660.

28. Grant JE, Chamberlain SR, Schreiber LR, Odlaug BL. Neurocognitive deficits associated with shoplifting in young adults. Compr Psychiatry. 2012;53(8):1049-55. doi:10.1016/j. comppsych.2012.04.012.

29. Aboujaoude E, Gamel N, Koran LM. Overview of kleptomania and phenomenological description of 40 patients. Prim Care Companion J Clin Psychiatry. 2004;6(6):244-7.

30. Talih FR. Kleptomania and potential exacerbating factors: a review and case report. Innov Clin Neurosci. 2011;8(10):35-9.

31. Odlaug BL, Grant JE, Kim SW. Suicide attempts in 107 adolescents and adults with kleptomania. Arch Suicide Res. 2012;16(4):34859. doi:10.1080/13811118.2013.722058.

32. Kindler S, Dannon PN, Iancu I, Sasson Y, Zohar J. Emergence of kleptomania during treatment for depression with serotonin 
selective reuptake inhibitors. Clin Neuropharmacol. 1997;20(2):126-9.

33. Shugaiv E, Kıyat-Atamer A, Tüzün E, Kürtüncü M, BaralKulaksızoğlu I, Akman Demir G. Kleptomania in patients with neuro-behçet's disease. Med Princ Pract. 2013;22(6): $550-4$.

34. Grant JE, Kim SW. Clinical characteristics and associated psychopathology of 22 patients with kleptomania. Compr Psychiatry. 2002;43(5):378-84.

35. Grant JE, Correia S, Brennan-Krohn T. White matter integrity in kleptomania: a pilot study. Psychiatry Res. 2006;147(2-3): 233-7. doi:10.1016/j.pscychresns.2006.03.003. Important study showing problems with white matter integrity, as has been reported in other substance use disorders.

36.• Grant JE, Kim SW, Odlaug BL. A double-blind, placebocontrolled study of the opiate antagonist, naltrexone, in the treatment of kleptomania. Biol Psychiatry. 2009;65(7):600-6. doi:10.1016/j.biopsych.2008.11.022. Important study showing the efficacy of naltrexone in the treatment of kleptomania, thus contributing to the concept of this condition as a behavioral addiction.

37. Koran LM, Aboujaoude EN, Gamel NN. Escitalopram treatment of kleptomania: an open-label trial followed by double-blind discontinuation. J Clin Psychiatry. 2007;68(3):422-7. 